\title{
Type 2 Diabetes and Cognitive Decline Over 14 Years in Middle-Aged African Americans and Whites: The ARIC Brain MRI Study
}

\author{
Elizabeth R. Mayeda ${ }^{a}$ Mary N. Haan ${ }^{a} \quad J o h n$ Neuhaus $^{a} \quad K^{2}$ ristine Yaffe ${ }^{a-c}$ \\ David S. Knopman $^{d}$ A. Richey Sharrett ${ }^{e}$ Michael E. Griswold ${ }^{f}$ Thomas H. Mosley ${ }^{g}$ \\ Departments of a Epidemiology and Biostatistics, ${ }^{b}$ Psychiatry, ${ }^{c}$ Neurology, University of California, San Francisco, Calif., \\ ${ }^{d}$ Department of Neurology, Mayo Clinic, Rochester, Minn., e Department of Epidemiology, Johns Hopkins University, \\ Baltimore, Md., ${ }^{f}$ Center of Biostatistics and Bioinformatics, University of Mississippi Medical Center, Jackson, Miss., and \\ gDepartment of Medicine, University of Mississippi Medical Center, Jackson, Miss., USA
}

\section{Key Words}

Diabetes $\cdot$ Cognitive decline $\cdot$ Ethnicity $\cdot$ Epidemiology

\begin{abstract}
Background: Diabetes predicts late-life dementia, but the association with rate of cognitive decline is inconsistent and has rarely been examined in non-white populations, despite the high prevalence of diabetes in African Americans. We evaluated the effect of diabetes on cognitive decline in middle-aged African Americans and whites. Methods: Atherosclerosis Risk in Communities (ARIC) Brain MRI Study participants ( $n=1,886$, mean age $=60,49 \%$ African American) underwent assessments of verbal memory, processing speed, and verbal fluency four times over 14 years. Using race-stratified mixed linear effects models, we examined cognitive change for participants with prevalent (baseline) diabetes and incident (diagnosed after baseline) diabetes versus those without diabetes. Results: African Americans had more advanced diabetes, as indicated by fasting blood glucose levels, anti-diabetes medication use, and cardiovascular risk profiles. African Americans with prevalent diabetes experienced $41 \%$ greater annual decline in processing speed scores $(p=$ 0.048 ) and $50 \%$ greater annual decline in verbal fluency scores $(p=0.042)$ than those without diabetes; incident dia-
\end{abstract}

betes was not associated with cognitive decline. Among whites, diabetes was not associated with cognitive decline. Conclusions: Prevalent diabetes was associated with greater cognitive decline in middle-aged African Americans, possibly reflecting adverse effects of longer duration and more advanced diabetes.

(c) 2014 S. Karger AG, Basel

\section{Introduction}

Mounting evidence suggests diabetes, diabetes severity, and high glucose levels are associated with dementia incidence in late-life ( $\geq$ age 65) [1-4]. Given the growing prevalence of diabetes [5] and population aging [6], the relationship between diabetes and dementia is of great importance. A recent meta-analysis of primarily crosssectional studies demonstrated that diabetes is associated with small-to-moderate decrements across cognitive domains, with largest effect sizes for motor function, executive function, and processing speed [7]. However, associations between diabetes and dementia or cognitive function at one point in time are susceptible to confounding from lifelong social experiences. Studies examining longitudinally-assessed cognitive decline are less

\section{KARGER}

E-Mail karger@karger.com

www.karger.com/ned (c) 2014 S. Karger AG, Basel

0251-5350/14/0434-0220\$39.50/0 


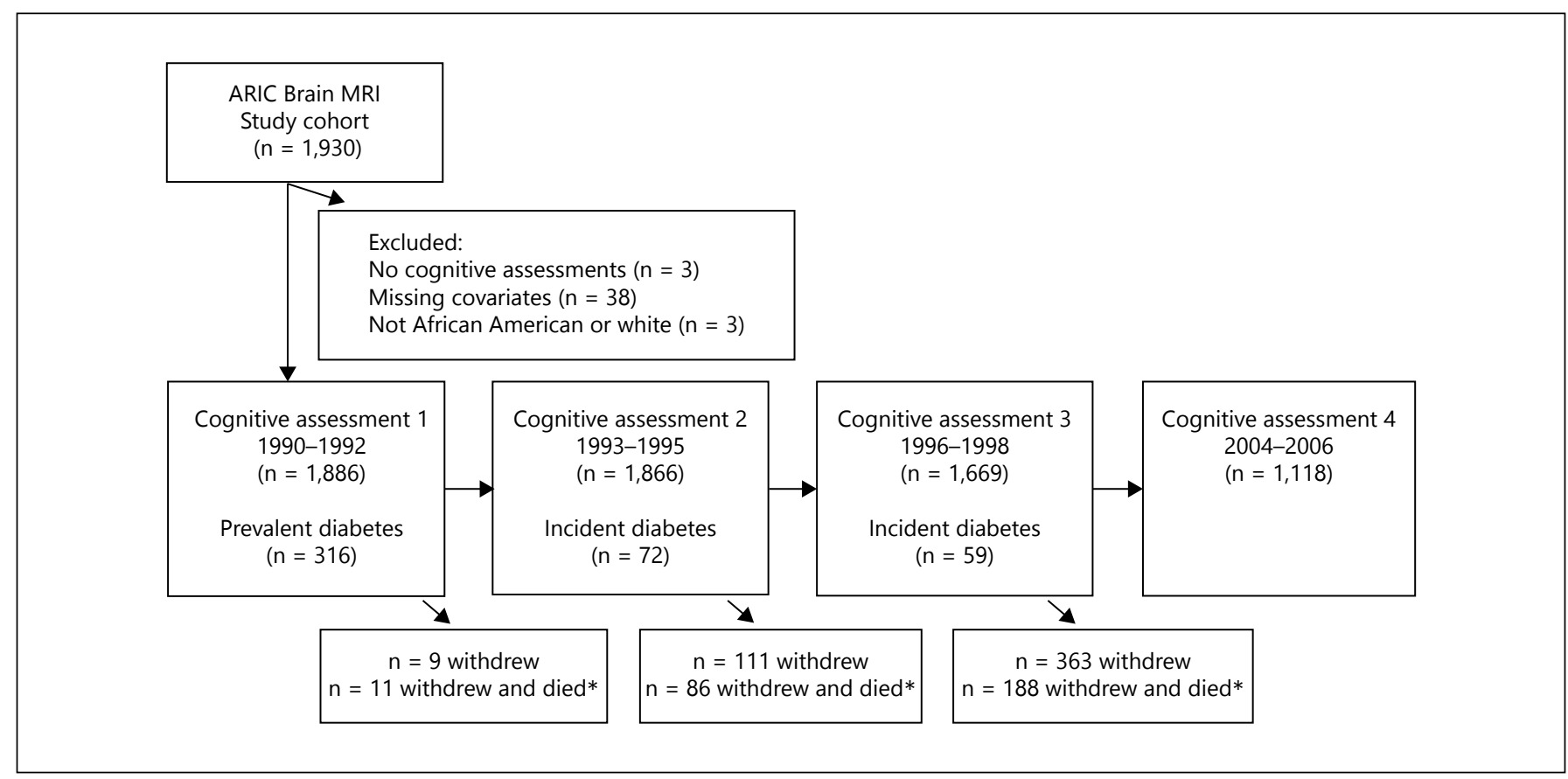

Fig. 1. Flow chart of study measurements. Cognitive assessments at each wave included Delayed Word Recall Test (DWRT), Digit Symbol Substitution Test (DSST), and first-letter Word Fluency

susceptible to confounding. Evaluating the association between diabetes and cognitive decline thus provides stronger evidence for the causal effects of diabetes and could inform strategies to prevent or delay dementia. Most studies on diabetes and cognitive decline have only examined prevalent diabetes measured at baseline, but recent studies suggest diabetes duration affects cognitive decline [8-11]. It is important to study this relationship in diverse populations, as variations in risk factor distributions may modify the association. Compared with whites, African Americans have higher diabetes prevalence [5], younger age at diagnosis [12], poorer quality diabetes care [13], and higher risk of some diabetes complications [13].

By focusing on the relationship between prevalent and incident diabetes and cognitive decline in middle-aged African Americans and whites (mean age 60), our study takes advantage of large race-specific sample sizes in the Atherosclerosis Risk in Communities (ARIC) Study and builds on previous work on diabetes and cognitive function, including in ARIC [14]. Our objective was to provide race-specific measures of association between prevalent and incident diabetes and changes in cognitive function over 14 years among African American and white middle-aged adults.

Diabetes and Cognitive Decline in MiddleAged African Americans and Whites
Test $($ WFT $)$. Incident diabetes $=$ Participant free of baseline diabetes and identified as having diabetes at the second or third cognitive assessment. * Deaths occurring during the study period.

\section{Materials and Methods}

\section{Study Sample}

ARIC is an ongoing community-based cohort study of 15,792 predominantly white and African American adults from four U.S. communities (Washington County, Maryland, Forsyth County, North Carolina, suburbs of Minneapolis, Minnesota, and Jackson, Mississippi) initiated in 1987-1989. The Jackson site enrolled a probability sample of African Americans aged 45-64; the other three sites included representative samples of both whites and African Americans aged 45-64 (details previously published) [15]. Cognitive function was first assessed at ARIC Exam 2 (1990-1992), considered baseline for the present analysis. At ARIC Exam 3 (1993-1995), participants aged $\geq 55$ from Forsyth County and Jackson were screened for eligibility for the ARIC Brain MRI (Magnetic Resonance Imaging) Study [16, 17]. For participant safety, exclusion criteria included contraindications for MRI. Of participants screened $(n=2,891), 2 \%$ of women and $6 \%$ of men were ineligible and $25 \%$ of women and $21 \%$ men declined to participate. ARIC Brain MRI Study participants ( $\mathrm{n}=$ 1,930) had cardiovascular risk factor profiles similar to those who declined to participate [16]. We used this sub-cohort even though brain MRI measures were not our focus because these participants underwent two additional cognitive assessments compared with the full ARIC cohort. This analysis excludes Brain MRI participants missing baseline information on diabetes, education, hypertension, or waist circumference $(n=38)$, who did not have cognitive assessments at any year $(\mathrm{n}=3)$, or were not African American or white $(n=3)$, for a final sample size of $n=1,886$ (fig. 1). 
Cognitive Function

ARIC Brain MRI Study participants underwent cognitive assessments at baseline (1990-1992) and years 3 (1993-1995), 6 (1996-1998), and 14 (2006-2008). Cognitive function was measured with three widely used cognitive tests: Delayed Word Recall Test (DWRT) [18], Digit Symbol Substitution Test (DSST) [19], and first-letter Word Fluency Test (WFT) [20] (details previously published) [21]. DWRT measures verbal learning and memory through delayed recall of 10 nouns; scores ranged from 0 to 10 . DSST measures processing speed through a 90 -second written task requiring translation of numbers to symbols using a key; baseline scores ranged from 0 to 85 . WFT measures verbal fluency by asking participants to generate as many words beginning with letters $\mathrm{F}, \mathrm{A}$, and $\mathrm{S}$ as possible in 60 seconds per letter; baseline scores ranged from 0 to 84 .

\section{Diabetes}

At cognitive assessments one, two, and three, participants were classified as having diabetes if they had fasting glucose level $\geq 7.0$ $\mathrm{mmol} / \mathrm{l}$ or non-fasting glucose level $\geq 11.1 \mathrm{mmol} / \mathrm{l}$ [22], self-reported physician diabetes diagnosis, or anti-diabetic medication use. Participants with diabetes at the baseline cognitive assessment were classified as having prevalent diabetes. Participants first identified as having diabetes at cognitive assessments two or three were classified as having incident diabetes.

\section{Covariates}

Demographic characteristics, including age, race, sex, and education (categorized as $\geq$ high school, high school or vocational school graduate, or $\geq$ high school (any college or professional school)) were collected by interview at the baseline ARIC examination. At the baseline cognitive assessment, seated blood pressure and waist circumference were measured, and stroke and myocardial infarction history were ascertained from interview. Hypertension was defined as systolic blood pressure $\geq 140 \mathrm{~mm} \mathrm{Hg}$, diastolic blood pressure $\geq 90 \mathrm{~mm} \mathrm{Hg}$, or anti-hypertension medication use.

\section{Mortality}

Mortality was ascertained through contact with next of kin and surveying discharge lists from local hospitals, local death notices, state health records, and the National Death Index. Death certificates were requested for all deaths.

\section{Statistical Methods}

To evaluate the effect of diabetes (prevalent, incident, or no diabetes) on rate of cognitive change, we fit race-specific, linearmixed effects models with random intercepts to examine the association between diabetes and cognitive decline with time (in years) from baseline cognitive assessment as the timescale. This method uses all available repeated measures and accounts for the fact that repeated measures on the same individual are correlated. A priori, we viewed the three cognitive tests as separate outcomes, so we did not apply the Bonferroni correction for multiple comparisons. There was little evidence of subject-specific heterogeneity in time: attempts to include random slope yielded random slope variance estimates of zero. We included two-way interaction terms between diabetes and time to examine differences in cognitive decline by diabetes status; the coefficient for the interaction term represents the mean difference in rate of change by diabetes status. We fit racespecific models to examine the association between diabetes and cognitive decline separately among African American and white participants. We also fit non-stratified models with three two-way interaction terms (diabetes*race, race*time, time*diabetes) and one three-way interaction term (diabetes*race*time). We adjusted for age (continuous, centered at 60 years), sex (reference $=$ male), education (reference $=$ high school graduate/vocational school), waist circumference (continuous, centered at 96 centimeters), and hypertension (reference $=$ no hypertension). The number of participants with history of stroke or myocardial infarction was low and adjustment for these factors did not influence estimates, so we excluded these variables from the final models.

We conducted three sensitivity analyses. First, to account for potential nonlinearities in cognitive change, we tried including linear spline terms in the linear mixed effects models for diabetes and cognitive decline. Second, to accommodate selective survival, we used joint models [23] composed of two sub-models with a shared random intercept for cognitive function: a linear mixed effects sub-model for cognitive decline and an exponential sub-model for mortality. Third, we excluded participants who scored in the lowest $3 \%$ on baseline cognitive tests.

Wherever possible, we followed guidelines for strengthening the reporting of observational studies in epidemiology [24].

\section{Results}

Participants were aged $48-70$ at baseline. Of the 1,886 participants, 23.8\% African Americans and 9.9\% whites had prevalent diabetes, 8.5\% African Americans and 5.4\% whites developed incident diabetes, and $67.7 \%$ African Americans and $84.7 \%$ whites had no diabetes (table 1). On average, participants with prevalent diabetes had less education, and participants with prevalent diabetes, followed by those with incident diabetes, had larger waists and were more likely to have hypertension and a history of stroke and myocardial infarction. African Americans were slightly younger, more likely to be female, had less education, larger waist circumferences and had approximately twice the prevalence of hypertension than whites.

Among participants with prevalent diabetes, African Americans were more likely to use anti-diabetic medication and had higher fasting blood glucose levels than whites (table 2). Anti-diabetic medication use was more prevalent and fasting blood glucose levels were higher among participants with prevalent diabetes than those with incident diabetes.

Table 3 displays results from adjusted race-specific mixed linear effects models examining mean differences in rate of change in cognitive function over time (per 10 years) by diabetes status. Results from unadjusted models were similar (not shown). Predicted cognitive trajectories from adjusted models are illustrated in figure 2 . The figure does not display confidence bounds, but precision of 
Table 1. Baseline characteristics of the sample by diabetes status and race

\begin{tabular}{|c|c|c|c|c|c|c|c|c|c|c|c|}
\hline & \multicolumn{4}{|c|}{ African American } & \multicolumn{4}{|l|}{ White } & \multirow{2}{*}{$\begin{array}{l}\text { African } \\
\text { American }\end{array}$} & \multirow[t]{2}{*}{ White } & \multirow[t]{2}{*}{$\mathrm{p}$} \\
\hline & $\begin{array}{l}\text { no } \\
\text { diabetes }\end{array}$ & $\begin{array}{l}\text { prevalent } \\
\text { diabetes }\end{array}$ & $\begin{array}{l}\text { incident } \\
\text { diabetes }\end{array}$ & $\mathrm{p}$ & $\begin{array}{l}\text { no } \\
\text { diabetes }\end{array}$ & $\begin{array}{l}\text { prevalent } \\
\text { diabetes }\end{array}$ & $\begin{array}{l}\text { incident } \\
\text { diabetes }\end{array}$ & $\mathrm{p}$ & & & \\
\hline $\mathrm{n}$ & 628 & 221 & 79 & & 811 & 95 & 52 & & 928 & 958 & \\
\hline Age, years & $59.2 \pm 4.5$ & $59.5 \pm 4.7$ & $59.4 \pm 4.4$ & 0.626 & $60.6 \pm 4.4$ & $61.1 \pm 4.3$ & $59.9 \pm 4.0$ & 0.256 & $59.3 \pm 4.5$ & $60.6 \pm 4.4$ & $<0.001$ \\
\hline Female sex, \% & 61.8 & 69.7 & 63.3 & 0.109 & 57.5 & 48.4 & 46.2 & 0.084 & 63.8 & 56.0 & $<0.001$ \\
\hline \multicolumn{12}{|l|}{ Education, \% } \\
\hline$<$ HS graduate & 37.9 & 46.2 & 36.7 & 0.047 & 13.2 & 24.2 & 21.2 & 0.009 & 39.8 & 14.7 & $<0.001$ \\
\hline HS/VS graduate & 24.7 & 27.6 & 27.9 & & 42.4 & 46.3 & 40.4 & & 25.7 & 42.7 & \\
\hline$>\mathrm{HS}$ & 37.4 & 26.2 & 35.4 & & 44.4 & 29.5 & 38.5 & & 34.6 & 42.6 & \\
\hline Waist circumference, $\mathrm{cm}$ & $96.6 \pm 12.3$ & $106.5 \pm 12.6$ & $106.2 \pm 13.1$ & $<0.001$ & $92.4 \pm 12.1$ & $104.7 \pm 14.2$ & $100.4 \pm 11.0$ & $<0.001$ & $99.8 \pm 13.3$ & $94.0 \pm 12.9$ & $<0.001$ \\
\hline \multicolumn{12}{|c|}{ Fasting blood glucose, $\mathrm{mmol} / \mathrm{l}$} \\
\hline Median & 5.7 & 8.6 & 6.3 & $<0.001$ & 5.5 & 7.9 & 6.1 & $<0.001$ & 5.9 & 5.6 & $<0.001$ \\
\hline 25th-75th percentile & $5.3-6.0$ & $7.4-13.6$ & $5.8-6.6$ & & $5.2-5.9$ & $7.2-9.9$ & $5.7-6.6$ & & $5.4-6.8$ & $5.3-6.1$ & \\
\hline Hypertension, \% & 48.9 & 64.7 & 63.3 & $<0.001$ & 22.0 & 41.1 & 40.4 & $<0.001$ & 53.9 & 24.8 & $<0.001$ \\
\hline Prevalent stroke, $\%$ & 1.3 & 5.4 & 2.5 & 0.002 & 1.2 & 6.3 & 3.9 & 0.002 & 2.4 & 1.9 & 0.450 \\
\hline Myocardial infarction, \% & 3.3 & 5.4 & 3.8 & 0.385 & 2.7 & 8.4 & 3.9 & 0.013 & 3.9 & 3.3 & 0.530 \\
\hline
\end{tabular}

Results are means $\pm S D$, percentages or median with percentiles. HS $=$ High school; VS = vocational school. $p$ values are for $\chi^{2}$ tests for categorical variables, ANOVA for age and waist circumference, and Wilcoxon test for fasting blood glucose.

Table 2. Diabetes characteristics at visit of diabetes diagnosis by prevalent vs. incident diabetes status

\begin{tabular}{|c|c|c|c|c|c|c|c|c|c|}
\hline & \multicolumn{3}{|c|}{ African American } & \multicolumn{3}{|l|}{ White } & \multicolumn{3}{|l|}{ Total } \\
\hline & $\begin{array}{l}\text { prevalent } \\
\text { diabetes }\end{array}$ & $\begin{array}{l}\text { incident } \\
\text { diabetes }\end{array}$ & $\mathrm{p}$ & $\begin{array}{l}\text { prevalent } \\
\text { diabetes }\end{array}$ & $\begin{array}{l}\text { incident } \\
\text { diabetes }\end{array}$ & $\mathrm{p}$ & $\begin{array}{l}\text { prevalent } \\
\text { diabetes }\end{array}$ & $\begin{array}{l}\text { incident } \\
\text { diabetes }\end{array}$ & $\mathrm{p}$ \\
\hline $\mathrm{n}$ & 221 & 79 & & 95 & 52 & & 316 & 131 & \\
\hline $\begin{array}{l}\text { Using anti-diabetic medication, } \% \\
\text { Fasting blood glucose, } \mathrm{mmol} / \mathrm{l}\end{array}$ & 59.9 & 18.0 & $<0.001$ & 36.3 & 15.7 & 0.009 & 52.6 & 17.1 & $<0.001$ \\
\hline
\end{tabular}

$\mathrm{p}$ values are for $\chi^{2}$ tests for anti-diabetic medication and Wilcoxon test for fasting blood glucose.

estimates can be assessed in table 3. Overall, African Americans scored lower on cognitive tests at baseline and experienced more decline than whites. Among African Americans, diabetes was not associated with greater decline on DWRT (verbal learning and memory test), but those with prevalent diabetes experienced greater decline on DSST (processing speed test) and WFT (verbal fluency test) than those without diabetes. Over 14 years, those with prevalent diabetes declined 1.7 more points on DSST (41\% greater decrease) and 1.6 more points on WFT (50\% greater decrease) than those without diabetes (based on estimates from table 3). Cognitive trajectories for African Americans with incident diabetes did not sig- nificantly differ from those without diabetes, and rate of change on DWRT and DSST did not significantly differ for those with incident versus prevalent diabetes, but participants with incident diabetes declined significantly less on WFT than those with prevalent diabetes $(\mathrm{p}=0.004)$. Among whites, cognitive trajectories were similar for those with prevalent diabetes, incident diabetes, and no diabetes. Although we observed an association between prevalent diabetes and cognitive decline among African Americans but not whites, three-way interactions in nonstratified models did not approach statistical significance: DWRT: race*prevalent diabetes*time $\mathrm{p}=0.47$, race*incidentdiabetes ${ }^{*}$ timep $=0.55 ; \mathrm{DSST}$ : race $^{*}$ prevalent 
Table 3. Results from race-specific linear mixed effects models for diabetes and rate of cognitive change per 10 years (presented as $b=$ regression coefficient)

\begin{tabular}{|c|c|c|c|c|}
\hline & \multicolumn{2}{|c|}{ African American $(n=928)$} & \multicolumn{2}{|l|}{ White $(\mathrm{n}=958)$} \\
\hline Intercept & $6.09(5.86$ to 6.33$)$ & $<0.0001$ & $6.60(6.43$ to 6.77$)$ & $<0.0001$ \\
\hline Time (10 years) & $-0.75(-1.01$ to -0.49$)$ & $<0.0001$ & $-0.53(-0.72$ to -0.34$)$ & $<0.0001$ \\
\hline Prevalent diabetes & $-0.47(-0.70$ to -0.25$)$ & $<0.0001$ & $-0.27(-0.55$ to 0.01$)$ & 0.062 \\
\hline Time*Prevalent diabetes & $0.02(-0.23$ to 0.28$)$ & 0.862 & $0.14(-0.22$ to 0.50$)$ & 0.459 \\
\hline Time*Incident diabetes & $-0.10(-0.45$ to 0.25$)$ & 0.566 & $0.07(-0.31$ to 0.46$)$ & 0.705 \\
\hline \multicolumn{5}{|l|}{ Digit Symbol Substitution test } \\
\hline Intercept & $28.53(26.91$ to 30.16$)$ & $<0.0001$ & $43.18(41.93$ to 44.42$)$ & $<0.0001$ \\
\hline Time (10 years) & $-2.92(-4.12$ to -1.72$)$ & $<0.0001$ & $-2.39(-3.19$ to -1.59$)$ & $<0.0001$ \\
\hline Prevalent diabetes & $-2.35(-3.91$ to -0.79$)$ & 0.003 & $-1.16(-3.18$ to 0.86$)$ & 0.261 \\
\hline \multicolumn{5}{|l|}{ Word Fluency Test } \\
\hline Intercept & $28.29(26.51$ to 30.06$)$ & $<0.0001$ & $31.89(30.51$ to 33.27$)$ & $<0.0001$ \\
\hline Time (10 years) & $-2.32(-3.44$ to -1.20$)$ & $<0.0001$ & $-0.24(-1.17$ to 0.68$)$ & 0.603 \\
\hline Prevalent diabetes & $-1.84(-3.54$ to -0.13$)$ & 0.034 & $-1.25(-3.50$ to 0.99$)$ & 0.274 \\
\hline Incident diabetes & $-3.28(-5.79$ to -0.78$)$ & 0.010 & $-0.31(-3.15$ to 2.53$)$ & 0.829 \\
\hline No diabetes & ref & & ref & \\
\hline Time*Prevalent diabetes & $-1.16(-2.27$ to -0.04$)$ & 0.042 & $0.46(-1.29$ to 2.22$)$ & 0.604 \\
\hline Time*Incident diabetes & $1.31(-0.17$ to 2.78$)$ & 0.083 & $0.73(-1.13$ to 2.59$)$ & 0.441 \\
\hline
\end{tabular}

Models are adjusted for age (centered at 60 years), sex (reference $=$ male), education (reference $=$ intermediate education $($ high school graduate/vocational school)), waist circumference (centered at 96 centimeters), and hypertension (reference $=$ no hypertension).

diabetes*time $\mathrm{p}=0.54$, race*incident diabetes*time $\mathrm{p}=$ 0.62; WFT: race*prevalent diabetes*time $\mathrm{p}=0.12$, race*incident diabetes*time $\mathrm{p}=0.65$.

Participants were followed for mean $=10.1$ years $(\mathrm{SD}=4.4)$. Throughout the study, $285(15.1 \%)$ participants died (African Americans: 13.5\% of no diabetes, $24.4 \%$ of prevalent diabetes, $15.2 \%$ of incident diabetes; whites: $11.6 \%$ of no diabetes, $31.6 \%$ of prevalent diabetes, $19.2 \%$ of incident diabetes), and an additional 483 (25.6\%) participants withdrew from the study (African Americans: $19.4 \%$ of no diabetes, $28.1 \%$ of prevalent diabetes, $13.9 \%$ of incident diabetes; whites: $30.3 \%$ of no diabetes, $33.7 \%$ of prevalent diabetes, $19.2 \%$ of incident diabetes).

In sensitivity analyses, results from models with linear spline terms and analyses that excluded participants who scored in the lowest $3 \%$ on baseline cognitive tests were qualitatively similar to the results from the main analysis. Results from joint longitudinal-survival models to ac- count for higher mortality rates among people with diabetes were similar to those from separate longitudinal models (table 2).

\section{Discussion}

Among middle-aged adults, prevalent diabetes at baseline was associated with accelerated 14-year decline in processing speed ( $41 \%$ greater decrease) and verbal fluency (50\% greater decrease) among African Americans. Among whites, we observed less change in cognitive test scores over time and no association between diabetes and cognitive decline.

Several factors may have contributed to our finding that prevalent diabetes was associated with accelerated cognitive decline among African Americans but not among whites. Due to historical and persistent inequalities, African Americans are differentially exposed to nu- 


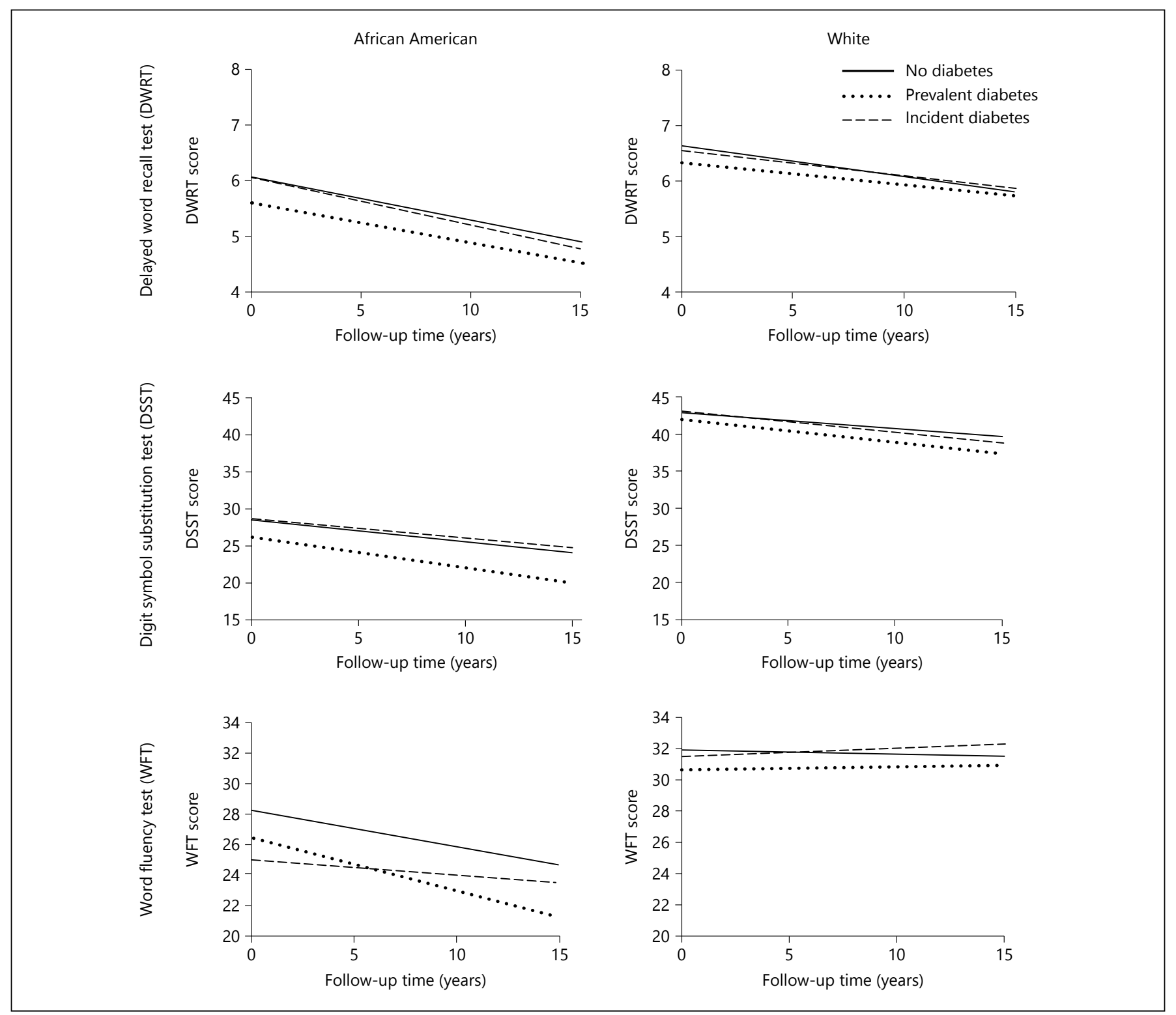

Fig. 2. Predicted cognitive trajectories by diabetes status from racespecific mixed linear effects models adjusted for age, sex, education, waist circumference, and hypertension. Shown for a 60 -year-

merous sociocultural factors that create health disparities $[25,26]$. In the present study, African Americans with prevalent diabetes had higher fasting blood glucose levels and were more likely to use anti-diabetes medication than whites with prevalent diabetes, which may represent more advanced disease. In national surveys, African Americans tend to be diagnosed with diabetes at younger ages than whites [12] and have poorer quality diabetes care [13]; these differences may contribute to the differences observed in the present cohort. Additionally, over-

old male with intermediate education (high school graduate or vocational school), waist circumference of 96 centimeters, and without hypertension.

all, African American participants had lower baseline test scores, which may reflect differences in level or quality of education or cultural factors that influence neuropsychological test performance [27, 28]. Lastly, African Americans had larger waist circumferences more than twice the prevalence hypertension as whites; although we controlled for these factors, unmeasured comorbidities may contribute to the observed differences.

Our finding that prevalent, but not incident, diabetes was associated with accelerated cognitive decline in 
African Americans is consistent with recent studies showing that longer diabetes duration is associated with accelerated cognitive decline [8-11]. Several studies of middleaged $(<$ age 65$)$ whites examined the association between diabetes and cognitive decline, reporting inconsistent findings across cognitive domains [10, 11,29]. While the Framingham Offspring Study reported no association between diabetes and cognitive decline [29], the Doetinchem Cohort Study reported that diabetes was associated with faster decline in memory and cognitive flexibility, but not processing speed [10], and the Whitehall II Study reported that diabetes was associated with faster decline in memory and reasoning, but not verbal fluency [11]. Several studies of white older adults have reported that diabetes is associated with accelerated decline in processing speed $[8,9,30]$, verbal fluency [31], and verbal memory $[9,32]$, while other studies have reported no association in these domains [31-33]. Differences in results across studies may be due to differences in study characteristics, including age, social factors, comorbidities, diabetes duration and severity, neuropsychological tests used, or because diabetes may have a modest effect on cognitive decline.

Knopman et al. previously investigated the relationship between prevalent diabetes and cognitive decline in ARIC and also found that prevalent diabetes was associated with accelerated decline on DSST and WFT, but not DWRT [14]. The present paper builds on this previous paper by examining the association between diabetes and cognitive decline separately by race and examining prevalent and incident diabetes. The two papers also handled attrition differently. The previous analysis was restricted to participants who remained on study through year 14 $(\mathrm{n}=1,130)$. Additionally, the present study includes a sensitivity analysis accounting for selective survival.

A limitation of this study is that the sample was composed of individuals who agreed to undergo brain MRI. Although Brain MRI participants had cardiovascular risk factor profiles similar to those who declined to participate, it is possible that participants included in this analysis differed from those who did not, which may impact generalizability of our results. The Jackson site included only African Americans and the Forsyth County site included more whites than African Americans [15], so differences between the two communities may contribute to observed differences by race. Although the cognitive test battery included widely used cognitive tests, there was only one test per domain and not all domains were assessed. Selective attrition (mortality and non-mortality) may lead to underestimation of the effect of diabetes on cognitive decline. Sensitivity analyses included joint longitudinal-survival models to address selective survival, but it is possible our approach did not fully overcome this issue. In addition to mortality-related attrition, which we accounted for in a sensitivity analysis, there was $25.6 \%$ non-mortality attrition.

This study has several notable strengths. ARIC is a community-based cohort study of middle-aged adults. Participants were followed starting around age 60, prior to substantial age-related cognitive decline, and followed for 14 years. The sample included substantial numbers of African Americans and whites, which enabled us to examine the two groups separately. This is important given the higher burden of diabetes among African Americans $[5,12,13]$. Further, we examined both incident and prevalent diabetes.

\section{Conclusion}

Prevalent diabetes was associated with $40-50 \%$ greater rate of decline in processing speed and verbal fluency among middle-aged African Americans, but not among whites. African Americans had higher fasting blood glucose levels and higher prevalence of anti-diabetic medication use than whites, which may represent more advanced diabetes. This has implications for accelerated cognitive decline and onset of dementia in late-life. Future studies should examine strategies to preserve cognitive function among middle-aged adults, particularly in populations highly burdened by diabetes.

\section{Acknowledgements and Funding}

The Atherosclerosis Risk in Communities Study is carried out as a collaborative study supported by National Heart, Lung, and Blood Institute contracts (HHSN268201100005C, HHSN268201 100006C, HHSN268201100007C, HHSN268201100008C, HHSN 268201100009C, HHSN268201100010C, HHSN268201100011C, and HHSN268201100012C). Neurocognitive data is collected by U01 HL096812, HL096814, HL096899, HL096902, HL096917 with previous brain MRI examinations funded by R01-HL70825. The authors thank the staff and participants of the ARIC study for their important contributions.

This work was also supported by the National Institute on Aging (grants AG-12975 and K24-AG031155).

\section{Disclosure Statement}

No conflicts of interest. 


\section{References}

-1 Biessels GJ, Strachan MW, Visseren FL, Kappelle LJ, Whitmer RA: Dementia and cognitive decline in type 2 diabetes and prediabetic stages: towards targeted interventions. Lancet Diabetes Endocrinol 2014;2:246-255.

$\checkmark 2$ Cheng G, Huang C, Deng H, Wang H: Diabetes as a risk factor for dementia and mild cognitive impairment: a meta-analysis of longitudinal studies. Intern Med J 2012;42:484-491.

-3 Crane PK, Walker R, Larson EB: Glucose levels and risk of dementia. N Engl J Med 2013; 369:1863-1864.

4 Exalto LG, Biessels GJ, Karter AJ, et al: Risk score for prediction of 10 year dementia risk in individuals with type 2 diabetes: a cohort study. Lancet Diabetes Endocrinol 2013;1: 183-190.

5 Centers for Disease Control and Prevention: National diabetes fact sheet: national estimates and general information on diabetes and prediabetes in the United States. 2011. http://www.cdc.gov/diabetes/pubs/pdf/ ndfs_2011.pdf.

6 Werner CA: The Older Population: 2010. Washington, DC, US Census Bureau, 2011.

7 Palta P, Schneider AL, Biessels GJ, Touradji P, Hill-Briggs F: Magnitude of cognitive dysfunction in adults with type 2 diabetes: a meta-analysis of six cognitive domains and the most frequently reported neuropsychological tests within domains. J Int Neuropsychol Soc 2014;20:278-291.

$\checkmark 8$ Yaffe K, Falvey C, Hamilton N, et al: Diabetes, glucose control, and 9-year cognitive decline among older adults without dementia. Arch Neurol 2012;69:1170-1175.

-9 Spauwen PJ, Kohler S, Verhey FR, Stehouwer $\mathrm{CD}$, van Boxtel MP: Effects of type 2 diabetes on 12-year cognitive change: results from the Maastricht Aging Study. Diabetes Care 2012.

$\checkmark 10$ Nooyens AC, Baan CA, Spijkerman AM, Verschuren WM: Type 2 diabetes and cognitive decline in middle-aged men and women: the Doetinchem Cohort Study. Diabetes Care 2010;33:1964-1969.

11 Tuligenga RH, Dugravot A, Tabák AG, et al: Midlife type 2 diabetes and poor glycaemic control as risk factors for cognitive decline in early old age: a post-hoc analysis of the Whitehall II cohort study. Lancet Diabetes Endocrinol 2014;2:228-235.
12 Centers for Disease Control and Prevention National Center for Health Statistics: Median Age at Diagnosis of Diabetes Among Adult Incident Cases Aged 18-79 Years, by Race/ Ethnicity, United States, 1997-2011. 2013 http://www.cdc.gov/diabetes/statistics/age/ fig4.htm (accessed June 6, 2014).

13 Lanting LC, Joung IM, Mackenbach JP, Lamberts SW, Bootsma AH: Ethnic differences in mortality, end-stage complications, and quality of care among diabetic patients: a review. Diabetes Care 2005;28:2280-2288.

14 Knopman DS, Mosley TH, Catellier DJ, Coker LH: Fourteen-year longitudinal study of vascular risk factors, APOE genotype, and cognition: the ARIC MRI Study. Alzheimers Dement 2009;5:207-214.

15 The Atherosclerosis Risk in Communities (ARIC) Study: design and objectives. The ARIC investigators. Am J Epidemiol 1989; 129:687-702.

16 Liao D, Cooper L, Cai J, et al: Presence and severity of cerebral white matter lesions and hypertension, its treatment, and its control. The ARIC Study. Atherosclerosis Risk in Communities Study. Stroke 1996;27:2262-2270.

17 Mosley TH Jr, Knopman DS, Catellier DJ, et al: Cerebral MRI findings and cognitive functioning: the Atherosclerosis Risk in Communities study. Neurology 2005;64:2056-2062.

18 Knopman DS, Ryberg S: A verbal memory test with high predictive accuracy for dementia of the Alzheimer type. Arch Neurol 1989;46: 141-145.

19 Wechsler D: Wechsler Memory Scale-Revised Manual. New York, NY, Psychological Corp., 1981.

20 Lezak MD: Neuropsychological Assessment, ed 2. New York, NY, Oxford University Press, 1983.

21 Cerhan JR, Folsom AR, Mortimer JA, et al: Correlates of cognitive function in middleaged adults. Atherosclerosis Risk in Communities (ARIC) Study Investigators. Gerontology 1998;44:95-105.

22 American Diabetes Association: Standards of medical care in diabetes - 2014. Diabetes Care 2014;37(suppl 1):S14-S80.
23 Guo X, Carlin BP: Separate and Joint Modeling of Longitudinal and Event Time Data Using Standard Computer Packages. The American Statistician 2004;58:16-24.

24 von Elm E, Altman DG, Egger M, et al: The Strengthening the Reporting of Observational Studies in Epidemiology (STROBE) statement: guidelines for reporting observational studies. Epidemiology 2007;18:800-804.

25 Williams DR: Race and health: basic questions, emerging directions. Ann Epidemiol 1997:7:322-333.

26 Glymour MM, Manly JJ: Lifecourse social conditions and racial and ethnic patterns of cognitive aging. Neuropsychol Rev 2008; 18 : 223-254.

27 Byrd DA, Touradji P, Tang MX, Manly JJ: Cancellation test performance in African American, Hispanic, and White elderly. J Int Neuropsychol Soc 2004;10:401-411.

28 Manly JJ: Race, Culture, Education, and Cognitive Test Performance Among Older Adults; in Hofer S, Alwin D (eds): Handbook of Cognitive Aging: Interdisciplinary Perspectives. Thousand Oaks, CA, SAGE Publications, Inc., 2008, pp 398-418.

29 Debette S, Seshadri S, Beiser A, et al: Midlife vascular risk factor exposure accelerates structural brain aging and cognitive decline. Neurology 2011;77:461-468

30 Arvanitakis Z, Wilson RS, Bienias JL, Evans DA, Bennett DA: Diabetes mellitus and risk of Alzheimer disease and decline in cognitive function. Arch Neurol 2004;61:661-666.

31 Kanaya AM, Barrett-Connor E, Gildengorin $\mathrm{G}$, Yaffe $\mathrm{K}$ : Change in cognitive function by glucose tolerance status in older adults: a 4 -year prospective study of the Rancho Bernardo study cohort. Arch Intern Med 2004; 164:1327-1333.

32 Comijs HC, Kriegsman DM, Dik MG, Deeg DJ, Jonker C, Stalman WA: Somatic chronic diseases and 6-year change in cognitive functioning among older persons. Arch Gerontol Geriatr 2009;48:191-196.

33 van den Berg E, de Craen AJ, Biessels GJ, Gussekloo J, Westendorp RG: The impact of diabetes mellitus on cognitive decline in the oldest of the old: a prospective populationbased study. Diabetologia 2006;49:20152023.
Diabetes and Cognitive Decline in MiddleAged African Americans and Whites
Neuroepidemiology 2014;43:220-227 DOI: $10.1159 / 000366506$ 